\title{
GAME-CONSTRUCTION STUDENTS EXPERIENCES OF EDUCATIONAL GAMES - GAMING OUTCOMES AND LEARNING OUTCOMES
}

\author{
Peter Mozelius
}

Department of Computer and Systems Sciences, Mid Sweden University, Östersund, Sweden \{Peter.Mozelius@miun.se\}

\begin{abstract}
Game-based learning has been a rapidly expanding field in the 21 th century, with research reports praising the motivational effects and learning outcomes of games. At the same time there have been doubts on the learning outcomes of even the most seriously designed learning games. The generation that today enrols for university programmes is in general a gaming generation, and game construction students are often so called hard core gamers. What are the game construction students' experiences of educational games, and what are their perceived learning outcomes?

This study is based on student essays on gaming habits and game-based learning outcomes, written by students taking a course on game-based learning. Essays from four course batches have been thematically analysed to answer the two research questions. Findings show that students have a rich experience of various kinds of games, but that they do not make any clear distinction between games developed for educational purposes, and other games. Students also perceive that there are cognitive, behavioural as well as affective learning outcomes from both standard entertainment games, and more serious learning games.
\end{abstract}

\section{KEYWORDS}

Game-based learning, GBL, Educational games, Serious games, Learning by gaming.

\section{INTRODUCTION}

Game-based learning (GBL) has been a hyped and emerging field in the 21th century. There have been several research reports on the strong learning potential of GBL, with the condition that games are carefully designed (Gee, 2007; Ebner \& Holzinger, 2007; Torrente et al., 2010; Reinhardt \& Sykes 2014; Wiggins, 2016). Another trend during the last decades is the 'myth dispellers', where the most ambitious dispellers analysis and discards around 50 myths at the same time (Lilienfeld et al., 2011; Jarrett, 2014). In the field of GBL and serious games, one published and quoted dispeller is Jeanne Farrington (2011).

In her quite shallow analysis serious games and simulations are seen as a 'research myth', with the recommendation to not invest in serious games development. The paper that can be found at ResearchGate, is hardly a methodical research study, and something written for a web column with the ambition to "... look at a recent entry in a series of 'serial myths'." (Farrington, 2011). Her column is mainly an analysis and a discussion of a study carried out by Sitzmann (2011), combined with material from blogs, other web resources and a few research papers. However, the article is published in several research repositories and part of the ongoing GBL debate. 
A recent and more thorough analysis of the learning potential of GBL is the literature study conducted by Vlachopoulos \& Makri (2017). The aim of their study was to discuss the impact of learning games and simulations with regard to achieving specific learning objectives. Three learning outcome categories were found for games integrated in educational settings, cognitive, behavioural, and affective, with 123 articles providing either empirical results or claiming meta-analytic evidence (Vlachopoulos \& Makri, 2017). However, as suggested by Vlachopoulos \& Makri, there is a need of further research and university instructors should take a more active role in the design and implementation of GBL in higher education.

Games and simulations are today widely integrated in higher education curricula, and there also exist many university programmes on game construction. Today, people are playing lots of digital games in general (Juul, 2010), and game construction students in particular (Mozelius, 2014). Most of these students have played different types of digital games since early childhood and spent considerable amounts of time in front of game screens. What are their perception of educational games, educational resources or so called Shavian reversals?

\subsection{Aim}

The aim of the study is to analyse and discuss students' perception of GBL and what they see as useful learning outcomes.

\subsection{Research questions}

Important research questions to answer in this study are:

1. What are game-construction students' experiences of educational games?

2. What are students perceived learning outcomes from playing educational games, categorised as cognitive, behavioural and affective?

\section{GAME-BASED LEARNING}

GBL has been a rapidly growing research field in the 21 st century with studies indicating promising results in various educational contexts (Tobias, Fletcher \& Wind, 2014). It would not be correct to classify GBL as a standalone didactic strategy, it should rather a concept that can and should be combined with other instructional design. GBL can today be seen as an integrated part of different educational concepts and built on various types of games and almost any initiative that combines gaming and education can be considered as GBL (Moreno-Ger et al. 2008).

Another related trend is gamification, which compared to gaming and playing, is more about gaming than playing since there are rules to follow. Gamification has been broadly defined as "the use of game design elements in non-game contexts" (Deterding et al., 2011), and more specifically defined for educational purposes as "using game-based mechanics, aesthetics, and game-thinking to engage people, motivate action, promote learning and solve problems." (Kapp, 2012, p. 10). A gamified system is designed to look and feel like a game but it does not go all the way (Olsson et al., 2015). Considering the students group taking a university programme on game construction, GBL was the natural choice since the curriculum is closely aligned to the idea of constructing games. Considering the essays, students' experiences of games are much richer than their experiences of gamification.

\subsection{Educational games and serious games}

GBL is in this article seen as transmedial, and not as in other studies exclusively as digital so called DGBL (Van Eck, 2006). Game ideas can be implemented in several ways, and analogue strategy games have been used in educational settings for thousands of years. Furthermore, this study does not make any clear distinction between commercial-of-the shelf (COTS) games and educational games. However, educational games can widely be defined as "games that are designed to teach someone something" (Moreno-Ger et al. 2008). 
The term Serious Games origins from the book 'Serious Games', where serious gaming refers to analogue board games and card games (Abt, 1987). Later the term was adopted by the Serious Games Initiative to refer to digital GBL and simulations (Marsh, 2011). With the fast technological and artistic development in the field of GBL it has been hard to define exactly what a serious game is. What seems like a good idea is to instead view serious games as the continuum presented by Tim Marsh (2011).

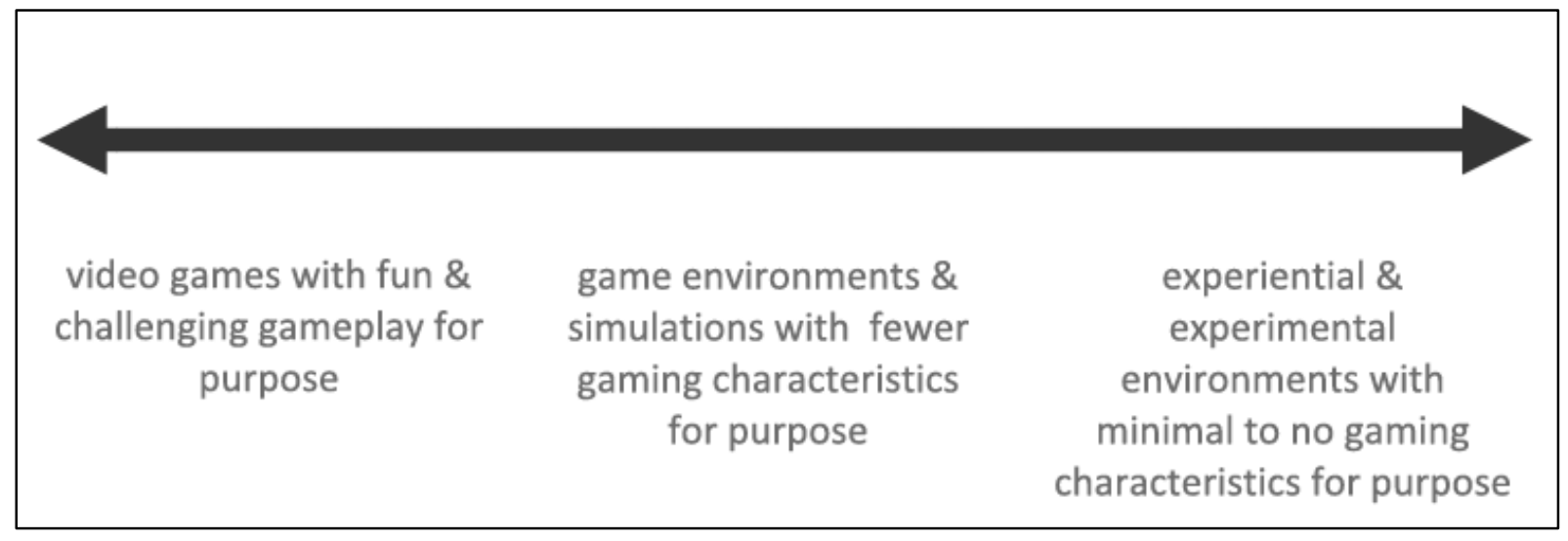

Figure 1. The serious games continuum (Marsh, 2011)

The games in the leftmost third are the traditional ones defined by Salen and Zimmerman (2003) as " . . a system in which players engage in an artificial conflict, defined by rules, that results in a quantifiable outcome", but with the extension that they should include a training and learning dimension. In the middle section games have less of traditional game characteristics and are more of digital media environments but still with entertaining game-like environment with a purpose to explore and learn. Finally, in the rightmost third the continuum encapsulates digital media environments with minimal to no traditional game mechanics with serious games mainly as interactive simulations. (Marsh, 2011)

\subsection{Shavian reversals}

The term Shavian reversal was coined in article by Seymour Papert (1998) where he criticises the contemporary "mating of education and entertainment". In an online dictionary that explains e-learning terminology Shavian reversals has been defined as: "A type of game in which the game and content are rarely integrated, which Seymour Papert calls Shavian Reversals, a term from genetics in which an offspring has inherited the worst characteristics of both parents" (E-learning Terminology, 2010).

This definition is correct in the sense that the term was coined by Seymour Papert, but the origin is not from genetics and based on a story featuring George Bernard Shaw and a famous beautiful woman. In the story the woman speculates about what a magnificent child they might have together if the child got her looks and Shaw's brain. According to the story Shaw's quick reply was: "But what if the child had my looks and your brains?" (Papert, 1998). The story is probably not true and a similar meeting has also been described between Albert Einstein and a chorus girl (Quote Investigator, 2013).

However, the term has been frequently used and discussed in GBL research (Peirce, Conlan \& Wade, 2008; Charsky, 2010; Söbke, Bröker, \& Kornadt, 2013). The phenomenon has sometimes been blamed on academicians who, in their game development process, have had little or no understanding of the art, science, and culture of game design (Van Eck, 2007). Despite the fact that much has happened in the design of educational and serious games since 1998 (Wechselberger, 2008), the term is still around in GBL discussions (Kronenberg, 2016; Wiemeyer \& Tremper, 2017). 


\section{INFORMANTS AND METHODS FOR DATA COLLECTION}

Data in study has been collected from four batches of students taking a university course on Game-based learning where the author is the course developer and the subject matter expert. Students have written essays on games, gaming habits and study habits. Essays were submitted in Moodle discussion fora where students also have posted their comments on two other submitted essays. Before writing the essay students have read suggested research papers on GBL to get familiar with concepts and learning theories that later should be discussed and related to in the essays. Students that did not find the suggested articles interesting have been free to choose their own GBL articles with concepts relevant to their essays. In all four course batches there have been a majority of male students and relatively few females, in the 2016 course batch there were 6 female and 27 male students.

All students are following a Bachelor's programme on Game construction and they are to be classified as digital gaming natives with extensive and sophisticated gaming habits (Mozelius et al., 2016).Students are digital gaming natives in the sense that almost all have started playing digital games as young as four to five years old. Non-gaming students have been rare and below $1 \%$ of the participants in the four student batches. The vast majority of the students also have all-embracing gaming habits and are, like so called hardcore gamers (Juul, 2010), playing in long and extensive game-sessions. (Mozelius et al., 2016) It seems realistic to assume that these student have high demands both considering gameplay and considering game design.

Data collected from the first three course batches have earlier been presented as conference papers (Mozelius, 2014; Mozelius et al., 2015; Mozelius et al., 2016) after content analysis of student essays and discussions at seminars. In this study earlier data has been reanalysed as a complement to the data gathered in the essays from 2016 version of the course. The earlier content analysis has now been replaced with a thematic analysis to find themes that can be useful when answering the two research questions. In contrast to the earlier content analyses where the frequency of found patterns are essential, the thematic analyses has had a focus on identifying themes that can be part of the answers to the research questions. The analyses has been conducted in six steps as recommended by Braun \& Clarke (2006): Step 1) Get familiar with data, Step 2) Generate preliminary codes, 3) Identify relevant themes, 4) Review found themes, 5) Define and name the themes, 6) Write up and present.

To answer the first research question an inductive analysis was conducted with a focus on the data collected in the 2016 course batch. Here students' essays were written to answer the question: What are your experiences of playing educational games? To answer the second research question a deductive analysis was carried out with the three learning outcomes categories presented by Vlachopoulos \& Makri (2017), as predefined analysis criteria. Students' perceived learning outcomes have been categorised and presented as cognitive, behavioural and affective. Essays in the 2013, 2014 and 2015 course versions have been written to answer the following questions:

- What are your experiences of playing games and have this has led to knowledge acquisition, new skills or learning stimulating effects? (Mozelius, 2014)

- What are your earlier gaming experiences and has the gaming led to any knowledge or skills that can be transferred and used in other contexts? (Mozelius et al., 2015)

- What are your gaming habits and how might excessive gaming disturbed your school studies or social activities? (Mozelius et al., 2016)

\section{FINDINGS AND DISCUSSIONS}

Found themes have been grouped separately try to answer the research questions one by one. Findings for research question 1 are separately presented and discussed under 4.1 and findings for research question 2 can be found under 4.2 . 


\subsection{Students experiences of educational games}

Findings in the essays from the 2016 batch strengthens the earlier findings that students have wide-ranging and extensive gaming habits, and that most students started to play games at an early age and often together with their parents (Mozelius, 2014; Mozelius et al., 2016). The excessive gaming and students' preference for long gaming sessions also is according to the idea of hard core gamers playing all kind of games and in long gaming sessions (Juul, 2010).

Many students write about memories of educational games on Mathematics from primary school, where some frequently played games were 'Matteraketen /Math rocket ', 'Flygande start / Flying start', 'Chefrens pyramid' and 'Cheops pyramid', which all are Swedish designed educational games, developed on purpose for school use in mathematical contexts. One female student remembers that she played Flygande start both in school and outside school and that "It didn't really feel like a learning game, and I played it mainly because it was fun". Most of the Math games have been played in school, but a male students tells that "My parents bought me the Math game 'Den flygande mattan / The flying carpet' to combine my strong game passion with something useful". There are different opinions about the learning outcomes, but students seem to agree on that the various Math games have increased their general motivation for Mathematics.

There are also reports on Swedish produced games with historical content that students have been playing them without viewing them as educational. One male student recalls "That 'Svea Rike' is an educational game wasn't anything I reflected on". Svea Rike that originally was an analogue board game on Swedish History in various eras, was never intended to be an educational game, the idea was rather to create a game for persons with a passion for History. With or without a passion for History, in one of the essays a student claims that "This game that doesn't have high immersion was, at least for me, a good way to learn History. As I remember, I was never interested or motivated for History classes, but this game gave me some motivation". Games on History can be hard to classify, but they are in general praised in the essays. Examples of well-designed COTS games where students say that they have learnt about History are: 'Age of Empires' and 'Civilization'. In Age of Empires every level is introduced with a History lesson where details to a high degree are correct.

That the essay writers have not made any clear distinction between educational games and other games is a found pattern for more types of games than the ones on History. Two other games that several students have hard to classify are 'Sim City' and 'Backpacker'. Most discussed in a long thread of its own is Backpacker, which also was one of the games that evoked a lot of nostalgia. A female student writes that "Backpacker has changed my opinion and made me see educational games as something enjoyable, where you also can learn something". She also brings up "What I see as the difference between Backpacker and 'chocolate covered broccoli-games' is that the mini-games are well integrated with the rest of the gameplay". Some more critical comments on the games' learning outcomes are "For every job you try you learn a little bit of everything, about mushroom picking, about how a radio works or how a newspaper is made, but all together rather superficial" and "Like many other kids I played a lot of Backpacker, but how about knowledge retention? I don't know if any important knowledge remains today". Two other students comments that the important lesson learnt in Backpacker is that, "abroad without money you call your parents for more".

It is two students in the 2016 batch that write that they have little experience of educational games. One of them writes that he finds educational games "to be uninteresting with simple game mechanics and poor graphical design" but also "... many educational games are boring seen as games, but in my opinion they can be a way to make education more interactive". The other student mentions a passion for mobile apps where you can learn to program. A game genre that he describes as "A grey zone between casual games and educational games". Casual, both in the sense of how casual games are defined with the possibility to play in short sessions and pause before the next session (Juul, 2010), and in the sense of casual games having a simplified gameplay. Examples given of this game genre are 'Code Avengers' and 'Learn 
JavaScript for Android ', quiz based games with questions on code syntax and basic programming techniques. Another game for learning to program and improve computational thinking is 'Human Resource Machine', which is described in an essay as "A kind of visual programming where you should make your avatar to correctly execute instructions". Another student wrote that "More of problem solving than to wrestle with messy syntax". A surprising finding was that many students brought up their experiences of 'The typing of the Dead', a learning game to improve the keyboard typing speed.

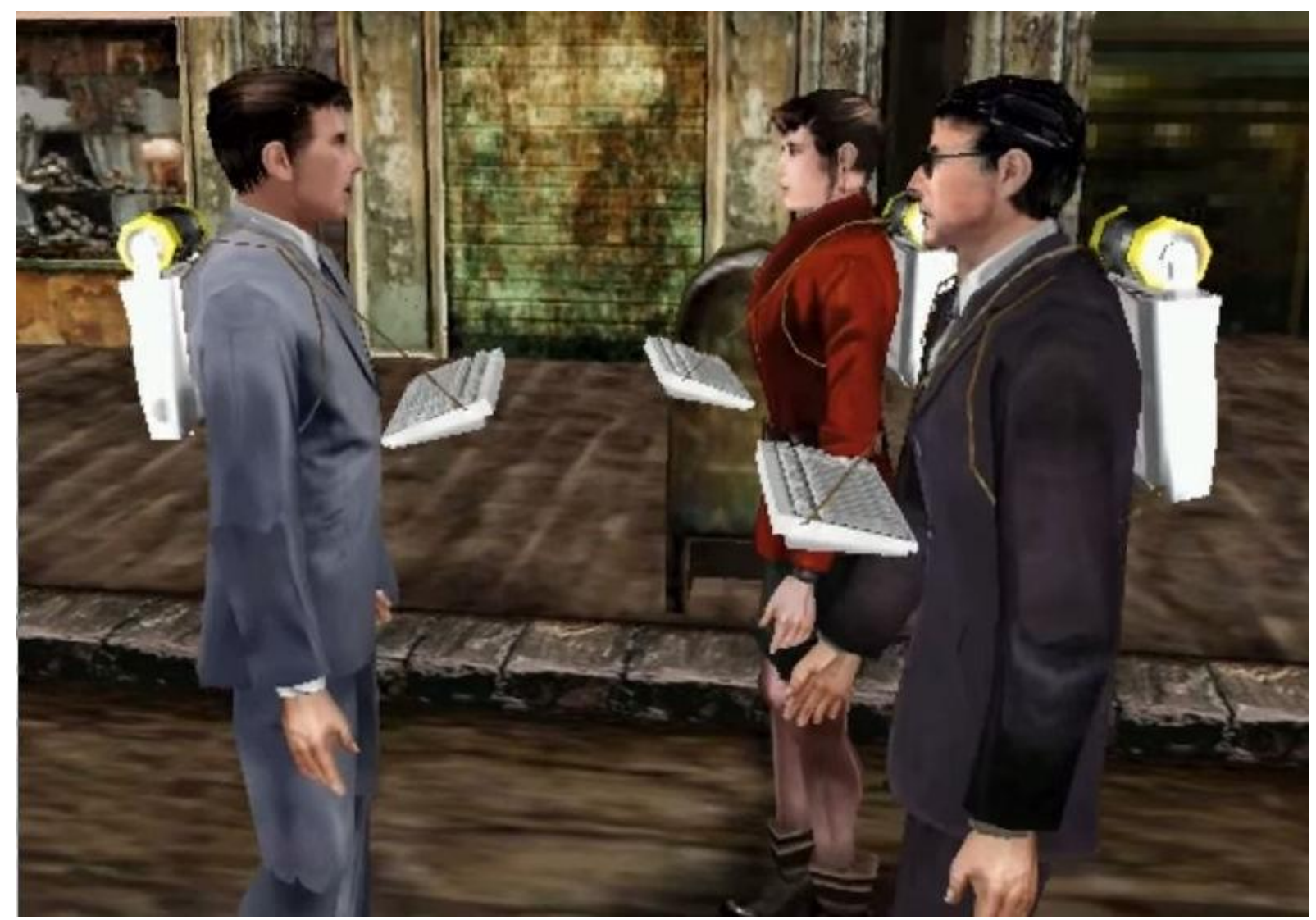

Image 1. The Typing of the Dead

The game is a remake of the light gun game 'The House of the Dead 2 ', where the ray guns are replaced by computer keyboards. In 'House of the Dead 2' the main characters are carrying ray guns, in 'Typing of the Dead ' the main characters are waking around with computer keyboards attached to a 'Dream Cast console'.

A student writes that "My main experience from educational games are the many hours that I've played 'The Typing of the Dead" and he also mentioned that "I definitely have to thank 'The Typing of the Dead' for my ability to type fast and correct on a keyboard, and unlike many other games that are designed for learning, this is a genuinely entertaining game worth playing merely for the sake of entertainment". Several students also mention that the competition factor in the gameplay contributes to the thrill. This also starts a discussion on games and competition, where some students claim that they find it exciting to compete, while others write that they dislike competition in gaming.

An interesting reflection in one of the comments is a male students' view of "older digital games", defined as games from the 20th century, as problem-based learning. He writes that "... to read the manual was a way to learn more English, and to be able to install the game required knowledge about how an operating system and file structures are organised". Problem-based learning is a didactic strategy that preferably can be combined with GBL and also natural part of constructionism (Papert \& Harel, 1991). Another male student writes about newer network games that "I've definitely learnt much English and quite a lot of technology related to network communication by playing games". 
Finally, an interesting question in an essay was "Take car simulations as an example, if it's possible to learn to drive a car entirely in a simulation (a game), wouldn't it be possible to transfer skills in other areas as well?". This bridges over to the next section on learning outcomes and if knowledge can be transferred and reused to other contexts. The question is based on earlier course discussions about two German racing game enthusiasts that won the Bathurst 12-hour race. The real world Bathurst race is one of the toughest endurance races in the world and the worlds' car racing expertise was stunned when the 2015 competition was won by two persons that have learnt to drive by playing video games (news.com.au., 2015).

\subsection{Students' perceived learning outcomes}

Essays from all four student batches have been analysed with found learning outcomes categorised as cognitive, behavioural, and affective. Cognitive outcomes are in this study defined as knowledge and skills acquisition that are transferable to other contexts, like language skills learnt in a game reused in real world conversations. Behavioural outcomes are defined as in the study by Ranchhod et al. (2014) as relational and teamwork skills, including concepts such as collaboration, interaction, team dynamics and leadership skills. Finally, affective outcomes are defined as how players' motivation and engagement are affected by playing games, and how games directly or indirectly can stimulate learning. An example of learning stimulation is the concept of tangential learning, with the meaning of joyful gaming stimulating further studies after playing the game (Portnow \& Floyd, 2008).

\section{Cognitive learning outcomes}

The least surprising, but most obvious finding is that both educational games and COTS games can improve players' language skills. What is most mentioned in the essays are about improved speaking skills where a male student wrote that "I had, of course, earlier learned English at school but mostly not by free will and mainly by reading and writing. In a World of Warcraft guild, I had for the first time the opportunity to speak English voluntarily in a relaxed environment with people that have English as their mother tongue. This has later been useful for communication with locals on holidays to New York, Croatia and London".

Two other students claim that "My overall gaming has had a huge impact on my English skills, they have clearly improved without any thoughts on how to learn ..." and "The most obvious example of what I learned was English, which also was confirmed by my teachers in school. They recognised a difference in the national test results between students who played digital games and the ones who didn't'. There are also other essays where students posit that their English improved English proficiency also includes grammar and writing skills "In tandem with my school activities online sessions in Battle.net accelerated my learning of English in primary school and during my 9th year in school I took a Cambridge certificate that affirms speaking as well as writing skills".

English is the by far most practiced language but a female student remembered that "In primary school I played educational games with exercises in English and Spanish, and even if I might have been too young to write in foreign languages I managed to build phrases by listening and image association in the games". Furthermore a male student stated "I would welcome a feature that, not only writes out the English names of the involved items, but also in Arabic and French...". Players' improved language proficiency from playing games have been reported in other research studies, where one of them is del Blanco, Marchiori \& Fernández-Manjón (2011).

Much can be argued about the importance of keyboard typing skills, but essays from all four course batches brings up the fascinating game 'Typing of the Dead '. Several students claim that their typing skills definitely have improved during hours of enjoyable gaming "The Typing of the Dead ' is a game where you have to type a lot of words that appears on the screen to avoid the zombies. If you manage to type the word the zombie that tries to catch you get killed. Playing this game has made me a very fast writer, where I'm always sure where the keys are placed on the keyboard and I never have to look at the keyboard". Another male student describes the game and the learning outcomes as "This game works like an excellent tool to improve something that is valuable today, the ability to type real fast on a computer keyboard. Since there 
are several monsters appearing at the same time you have to constantly focus on the screen, not to miss the words and phrases you should enter. The trick to speed up your typing pace is to stop looking at the keyboard and you learn a superfast automatic way of typing”. Whatever the opinions on zombies and keyboard typing the learning outcomes seem to be obvious.

Regarding games a bit to the right in the serious games continuum (Marsh, 2011) several student essays have mentioned the Sweden developed Bonnier's Car School / Bonniers Bilskola, a gamified version of the theoretical test for the Swedish driving licence. Both male and female students find the game useful and one student writes that, "... this game definitely helped me without ever giving me the feeling of studying when I switched on the computer". To get a Swedish driving licence is an expensive process and that a welldesigned serious game can facilitate: "Bonniers trafikskola was an efficient tool where I could learn and test what I've learned in a multi-media environment instead of only reading the theory book. My clearest memories are of the images depicting various traffic situations from where you should tell how the cars should act and interact. I also learned about the different parts of a car and its engine".

Serious games and simulations seem to be where learning outcomes are easiest to prove with examples brought up in the essays. One example is the earlier mentioned German gamers that participated in the real world Bathurst race (news.com.au., 2015). Another example involving simulators mentioned in an essay is the case of the infamous 'Swedish fake pilot'. Without any pilot licence, except for a home-made one, he worked as a pilot for several international airline companies during 13 years. How to fly passenger planes was something he learnt during night sessions with SAS owned flight simulators at the Arlanda airport in Sweden. (Daily Mail Online, 2010) The Scandinavian airline company SAS is just one of many airline companies that use simulators in their pilot training with a cost of hundreds of Euro per hour (Scandinavian Aviation Academy, 2017).

\section{Behavioural learning outcomes}

Two types of games where strong emotions are involved are 'First-person shooter games' (FPSs) and 'Massively Multiplayer Online Role-Playing Games' (MMORPGs). The two most frequently played are 'Counter Strike' (FPS) and 'World of Warcraft' (MMORPGs), where both games have high status and at the same time with a risk for addictive gaming (Mozelius et al., 2016). Several students bring up learning outcomes from FPSs and MMORPGs, a male student stated that "I've definitely learnt most from COTS in my gaming life. World of Warcraft has for me been like a long exercise on talking and writing English, collaborating with other people and problem solving". Another male student posits that "I've played World of Warcraft for a long time and most of the time you collaborate in groups ..., what I've learnt from this is to collaborate and to get info from multiple sources".

Several essays in all four student batches have brought up the idea of improved communication skills and improved social skills as an outcome from playing online games, a male student in the first course batch claimed that "...the virtual world has its own values where you have to create contacts and build a social life just like in real life". A female Counter Strike (CS) player from the same course batch wrote "CS functioned a bit like any other social media with chats where people chatted about all kind of things and not only CS related topics". There also exist several testimonies about improved leadership skills from playing MMORPGs, where a male student from the last course batch posited "By playing World of Warcraft with people from many different countries I've also developed my leadership skills, when I've been leading raids with 24 other gamers".

Except from the female Counter Strike player, the worlds of FPSs and MMORPGs seem to be strongly male dominated. A more girly game with behavioural learning outcomes seems to be 'The Sims', where the virtual characters can get sad, moody and even depressed when they are isolated without communications with other 'Sims'. Another female student see 'The Sims' as a way to improved strategic skills that later have been useful in daily life situations. Two games that seems to be played by mostly boys are the football based 'FIFA Manager' and the ice-hockey game 'NHL'. A male student described his experience of NHK 13 as "Except from playing against other persons you can play together with friends. In the beginning it 
was like a grey-zone where we didn't really understand each other. But the more we played on the smoother the collaboration. There is a certain feeling after a successful attack resulting in a beautiful goal".

An extraordinary example of how behavioural/cognitive learning outcomes can be transferred to other context was found in an essay where the student remembers that "I've learnt to cope with stressful situations in computer games" and "... some years ago there was a sudden earthquake in Japan, and of course I got frightened and worried but I pulled myself together and remembered the training from a computer game. Get down under a table, cover your head, wait until the quake ceases and don 't be close to windows". The same student also concludes his essay with the recommendation: "Accordingly I would like to encourage everybody to play as much as you can, because you never now, it might one day save your life!".

\section{Affective learning outcomes}

A game mentioned in some essays is SIM City and a reflection from a male student was "This is not a game that has a focus on teaching advanced city planning, but on the under hand it's built around that with certain aspects that you have to consider. Which can be stimulating and inspire you to learn more". Another student wrote "This (SIM City) is a game that in a longer perspective can make you interested in city planning" and "It is because of Japanese games that I, in the future, want to be a game designer in Japan".

Other games described to have learning stimulating effects are 'Civilization' and 'Age of Empires', where both games touches upon the concept of tangential learning. The fundamental idea of tangential learning is that a game should introduce a theme or a technique to inspire learners to further self-studies (Portnow \& Floyd, 2008). Instead of a traditional direct teaching and learning setup, a game could engage and stimulate learning by presenting abstract knowledge in an attractive and motivating context. Civilization is a game that has built-in 'Civilopedias' containing information about the civilizations that the player is related to in the gameplay. 'Age of Empires' has History lectures built-in between the various levels in the game.

Many students have played various types of Math games during their time in primary school and several essays mention the motivational effect. One male student has, just a few years ago worked as an assisting primary school teacher, in his essay he describes the situation some years ago as "Something I recognised in the school where I worked was that several kids had lost their joy and motivation, as early as 7-8 years old" and "... it was a fascinating experience that students that earlier didn't solve more than just a few assignments per lesson, now sat down after class and tried to get further on in the game". That Math games can increase students' motivation for Mathematics was also a finding in the study conducted by Gunter, Kenny \& Vick (2008).

Why the Math games are motivating is hard to pinpoint, but two explanations found in the essays are that games visualise the problems and that the games are built around competition. Regarding visualisation a male student raised the question "Why should it be better to solve assignments on a screen than in a paper book? ". His own answer was "An important reason is that in 'Chefren's Pyramid' the Math problems are visualised in a challenging way. And if you solve the problem you will be rewarded". 'Chefren's Pyramid' is also built around competition which a male student described as "The external motivation is to compete with your classmates, which was an important motivation for me". But in another essay a female student recalls that "... the competition can result in a backlash for students that are not that good at Mathematics and have a negative effect on bad losers (like me)".

Competition games or collaboration games, many essays mention the motivational effects. As early as in the 1980s Thomas Malone and Frank Leppard found that digital games could kick-start strong intrinsic motivation (Malone \& Lepper, 1987). With the improved computer graphics and game design in the 21 st century, it is realistic to assume that digital games today can create stronger states of intrinsic motivation than 30 years ago. 


\section{CONCLUSION}

One obvious finding is that the students do not have a clear distinction between educational games and other types of games, the first encounter with an educational game was in some essays described as by random. A student writes that "I started playing it thinking that is was a regular Mario game, but it turned out to be an educational game". This can also be related to students' perceived learning outcomes, where students claim that they have learnt various things from various types of games, from COTS games and from different parts in the serious games continuum and that one student claims that "Most gaming leads to some kind of learning". However, there have also been descriptions in the essays of games that could be classified as Shavian reversals, and some students have claimed that they are reluctant to educational games in general.

Considering the second research question there are several findings supporting the idea of cognitive learning outcomes from playing games. The cognitive learning outcomes that are most obvious are improved language skills, and according to the student essays this goes for most kind of games. That serious games, seriously combined with teaching and learning sessions, improves learners language skills have been shown earlier in other studies as well (Johnson, 2007). The findings from this study implies that this hols for other subjects as well.

There were also several testimonies on how games can motivate and engage players, which is an idea that was investigated as early as in the 1980s (Malone \& Lepper, 1987). Today, three decades later, with a wide variety of digital games, there are strong reasons to assume that the affective learning outcomes are even stronger. There also exist research studies that indicates that well-designed and challenging games, can have a positive effect on learning outcomes both directly and indirectly via an increased engagement (Hamari et al., 2016).

Finally, it is hard to draw any conclusions on behavioural learning outcomes based on the data collection in this study, but students' perception is that playing FPSs and MMORPGs could improve social skills. There are also claims in some essays that collaborative gaming might strengthen students' leadership skills and the ability to handle stress. There would for several reasons be interesting to design and develop educational/serious games based on the MMORPG concept.

\section{REFERENCES}

Abt, C. C. (1987). Serious games. University press of America.

Braun, V. and Clarke, V. (2006). Using thematic analysis in psychology. Qualitative Research in Psychology, 3 (2). pp. 77-101.

Charsky, D. (2010). From edutainment to serious games: A change in the use of game characteristics. Games and culture, 5(2), 177-198.

Daily Mail Online (2010). "Fake Swedish air pilot flies passenger jets for THIRTEEN YEARS without a licence... and is fined just £1,700" (Retrieved 26/07/2017) from: http://www.dailymail.co.uk/news/article1279083/Fake-Swedish-pilot-Thomas-Salme-flies-Air-One-jets-13-years.html\#ixzz4oL1BWcId

del Blanco, Á., Marchiori, E., \& Fernández-Manjón, B. (2011) Adventure Games and Language Learning. Technological Innovation in the Teaching and Processing of Lsps: Proceedings of Tislid'10, 243.

Deterding, S., Dixon, D., Khaled, R., \& Nacke, L. (2011, September). From game design elements to gamefulness: defining gamification. In Proceedings of the 15th international academic MindTrek conference: Envisioning future media environments (pp. 9-15). ACM.

Ebner, M., \& Holzinger, A. (2007). Successful implementation of user-centered game based learning in higher education: An example from civil engineering. Computers \& education, 49(3), 873-890.

E-learning Terminology (2010). ”E-learning Faculty Modules” (Retrieved 15/07/2017) from: 
http://elearningfacultymodules.org/index.php/E-Learning_Terminology

Farrington, J. (2011). From the research: myths worth dispelling: seriously, the game is up. Performance Improvement Quarterly, 24(2), 105-110.

Gunter, G.A., Kenny, R.F. \& Vick, E.H. (2008). "Taking educational games seriously: using the RETAIN model to design endogenous fantasy into standalone educational games", Educational Technology Research, Springer

Gee, J. P. (2007). What video games have to teach us about learning and literacy, New York: Palgrave Macmillan.

Hamari, J., Shernoff, D. J., Rowe, E., Coller, B., Asbell-Clarke, J., \& Edwards, T. (2016). Challenging games help students learn: An empirical study on engagement, flow and immersion in game-based learning. Computers in Human Behavior, 54, 170-179.

Jarrett, C. (2014). Great myths of the brain. John Wiley \& Sons.

Johnson, W. L. (2007). Serious use of a serious game for language learning. Frontiers in Artificial Intelligence and Applications, 158, 67.

Juul, J. (2010). A casual revolution: Reinventing video games and their players. MIT press.

Kapp, K. M. (2012). The gamification of learning and instruction: game-based methods and strategies for training and education. John Wiley \& Sons.

Kronenberg, F. A. (2016). Selection criteria for commercial off-the-shelf (COTS) video games for language learning. IALLT Journal of Language Learning Technologies, 42(2).

Lilienfeld, S. O., Lynn, S. J., Ruscio, J., \& Beyerstein, B. L. (2011). 50 great myths of popular psychology: Shattering widespread misconceptions about human behavior. John Wiley \& Sons.

Malone, T. W. \& Lepper, M. R. (1987). Making learning fun: A taxonomy of intrinsic motivations for learning. Aptitude, learning, and instruction, 3, 223-253.

Marsh, T. (2011). Serious games continuum: Between games for purpose and experiential environments for purpose. Entertainment Computing, 2(2), 61-68.

Moreno-Ger, P., Burgos, D., Martínez-Ortiz, I., Sierra, J.L. \& Fernández-Manjón, B. (2008). Educational game design for online education, Computers in Human Behavior.

Mozelius, P. (2014). What can be Learned From Playing Digital Games Outside School. In 8th European Conference on Games Based Learning: ECGBL2014 (p. 415).

Mozelius, P., Wiklund, M., Westin, T., \& Norberg, L. (2015). Transfer of knowledge and skills from computer gaming to non-digital real world contexts. In International Conference on e-Learning (p. 235). Academic Conferences International Limited.

Mozelius, P., Westin, T., Wiklund, M., \& Norberg, L. (2016). Gaming habits, study habits and compulsive gaming among digital gaming natives. In European Conference on Games Based Learning (p. 486). Academic Conferences International Limited.

Olsson, M., Mozelius, P., \& Collin, J. (2015). Visualisation and Gamification of e-Learning and Programming Education. Electronic Journal of e-Learning, 13(6), 441-454.

news.com.au (2015). Nissan wins the Bathurst 12 Hour with GT Academy drivers behind the wheel. Retrieved (22/07/2017) from: http://www.news.com.au/technology/innovation/motoring/nissan-wins-thebathurst-12hour-with-gt-academy-drivers-behind thewheel/newsstory/12d0586ef7cae44974de9e52db69e4e4 
Papert, S. (1998) Does easy do it? Children, games and learning, In: Game developer magazine, June, p. 88

Papert, S., \& Harel, I. (1991). Situating constructionism. Constructionism, 36(2), 1-11.

Portnow, J., \& Floyd, D. (2008). The power of tangential learning. Edge Online.

Quote Investigator (2013) "But Suppose the Child Inherited My Beauty and Your Brains?", (Retrieved 15/072017) from http://quoteinvestigator.com/2013/04/19/brains-beauty/

Ranchhod, A., Gurău, C., Loukis, E., \& Trivedi, R. (2014). Evaluating the educational effectiveness of simulation games: A value generation model. Information Sciences, 264, 75-90.

Reinhardt, J., \& Sykes, J. M. (2014). Digital Game and Play Activity in L2 Teaching and Learning. Language, Learning \& Technology, 18(2), 2.

Salen, K. \& Zimmerman, E. (2003). Rules of Play: Game Design Fundamentals, The MIT Press.

Scandinavian Aviation Academy (2017). "Become a world-class pilot" (Retrieved 26/07/2017) from: https://www.bfsaa.se/en

Sitzmann, T. (2011). A meta-analytic examination of the instructional effectiveness of computer-based simulation games. Personnel psychology, 64(2), 489-528.

Söbke, H., Bröker, T., \& Kornadt, O. (2013). Using the master copy-adding educational content to commercial video games. In European Conference on Games Based Learning (p. 521). Academic Conferences International Limited.

Tobias, S., Fletcher, J. D., \& Wind, A. P. (2014). Game-based learning. In Handbook of research on educational communications and technology (pp. 485-503). Springer New York.

Van Eck, R. (2006). Digital game-based learning: It's not just the digital natives who are restless. EDUCAUSE review, 41(2), 16.

Vlachopoulos, D. \& Makri, A. (2017). The effect of games and simulations on higher education: a systematic literature review, International Journal of Educational Technology in Higher Education 14:22 Wechselberger, U. (2008). The eduventure ii. an approach to educational game design. In Cyberworlds, 2008 International Conference (pp. 397-404). IEEE

Wiemeyer, J., \& Tremper, L. L. (2017). Edutainment in Sport and Health 35. Handbook of Digital Games and Entertainment Technologies, 883.

Wiggins, B. E. (2016). An Overview and Study on the Use of Games, Simulations, and Gamification in Higher Education. International Journal of Game-Based Learning (IJGBL), 6, 18-29. 